\title{
Reduced dopamine function in depressed patients is related to suicidal behavior but not its lethality
}

\author{
William Pitchot *, Michel Hansenne, Antonio Gonzalez \\ Moreno, Emmanuel Pinto, Jean Reggers, Sonia Fuchs, \\ Sandrine Pirard, Marc Ansseau
}

Psychiatric Unit, CHU Sart Tilman, B-4000 Liège, Belgium

Received 20 October 2000; received in revised form 8 February 2001; accepted 10 February 2001

\begin{abstract}
Several lines of evidence suggest a role for dopamine in the control of suicidal behaviour. Previously, we suggested an involvement of D2-dopaminergic function in the biology of suicide by demonstrating a smaller growth hormone $(\mathrm{GH})$ response to apomorphine, a dopaminergic agonist, in depressed patients who later died by suicide. The purpose of the present study was to assess GH response to apomorphine in major depressed in-patients with a history of highly lethal suicide attempt compared to depressed patients with a low lethal lifetime suicide attempt history and non-attempters. The study was performed in a sample of 26 male depressed in-patients with a history of suicide attempt compared to 26 male depressed nonattempters. We observed a significant difference between suicide attempters and non-attempters (for $\mathrm{GH}$ peak, $6.3 \pm 5.1 \mathrm{ng} / \mathrm{ml}$ vs $15.8 \pm 14.2 \mathrm{ng} / \mathrm{ml}, F=10.3$, df=1, 50, $P=0.002$ ). Moreover, GH peak responses to apomorphine did not differ between depressed patients with a high lethal lifetime suicide attempt history and patients who made low lethal lifetime suicide attempt. In conclusion, the results of the present study support a role for dopamine in the biology of suicidal behaviour. More specifically, an impaired GH response to apomorphine could be a marker of suicide risk. (c) 2001 Elsevier Science Ltd. All rights reserved.
\end{abstract}

Keywords: Depression; Suicide attempt; Dopamine; D2 receptors; Neuroendocrine test

* Corresponding author. Tel.: +32-4-366-7960; fax: +32-4-366-7283.

E-mail address: wpitchot@chu.ulg.ac.be (W. Pitchot). 


\section{Introduction}

An impaired serotonergic activity has been extensively observed in different psychiatric diagnostic categories such as depression, anxiety, schizophrenia, alcoholism and personality disorders. Suicidal dimension could be a common link between these psychiatric disorders. Indeed, suicidality has been associated with low cerebrospinal fluid 5-hydroxyindolacetic acid (5-HIAA) concentration across several diagnostic entities in a large number of studies (Asberg, 1997). The role of serotonin as a biological correlate of suicidal behavior has also been proposed in post-mortem, platelet and neuroendocrine studies, but with some inconsistent results (Pandey, 1997; Mann and Stoff, 1997). A reduced serotonergic function has been consistently observed in patients with a history of high-lethality suicide attempt or in those with a high level of impulsivity (Mann and Malone, 1997).

The role of the dopaminergic system has been less extensively evaluated. Postmortem studies have provided conflicting results. In 1984, Crow et al. reported an increase in homovanillic acid (HVA) concentration in the hippocampus, but not the cortex, of suicide victims. Ohmori et al. (1992) observed an increase in HVA concentrations in the frontal cortex of individuals who committed suicide compared to subjects who died by a physical illness. Bowden et al. (1997) provided results supporting reduced dopamine turnover in depressed suicides by demonstrating decreased dihydroxyphenylacetic acid (DOPA) in the basal ganglia of suicide completers who died by non-violent means. In contrast, Arranz et al. (1997) did not find any difference in cortical HVA concentrations between suicide victims and controls. Several studies assessing dopaminergic function by measuring CSF dopaminergic metabolites in suicide attempters have suggested an association between dopamine hypoactivity and suicidality. Low levels of CSF HVA have been found in depressed patients with a history of either violent or non-violent suicide attempts than in controls (reviewed by Engström et al., 1999). In a five year longitudinal study, Roy et al. (1989) observed that patients who reattempted suicide during the follow-up period had lower CSF HVA concentrations compared to controls. This predictive value of low CSF HVA concentrations has been confirmed in another longitudinal study over a period of two years (Träskman-Bendz et al., 1993). Recently, Engström et al. (1999) showed reduced CSF HVA concentrations and HVA/5-HIAA ratios in suicide attempters compared to controls. Moreover, it has been suggested that low CSF HVA concentrations could be a more reliable index of suicidal behavior than low CSF 5-HIAA (Roy et al., 1986). In contrast, Mann and Malone (1997) did not find any association between CSF HVA concentrations and suicidality in depressed suicide attempters with a high degree of lethality. Mann and Malone emphasized that suicide attempt is a complex dimension compared to suicide completion. Indeed, some suicide attempts generally called failed suicide involve a real intent to die and are frequently associated with significant medical damage and the use of high lethality methods, whereas other attempts called "parasuicide" involve little medical damage and low lethality methods. In fact, both categories are parts of a large spectrum of suicidal behaviour. In this context, studies assessing biological correlates of suicidal behavior should 
take account of the real nature of suicide attempt and in paticular the real lethality of the attempt.

In 1992, we suggested an involvement of D2-dopaminergic function in the expression of suicidal behavior by demonstrating a smaller growth hormone $(\mathrm{GH})$ response to apomorphine, a dopaminergic agonist, in depressed patients with a history of suicide attempts in comparison to non-attempters (Pitchot et al., 1992). More recently, we confirmed this observation in a sample of non-depressed suicide attempters (Pitchot et al, personal results) and in major depressed patients who died by suicide within one year of neuroendocrine assessment (Pitchot et al., 2001). The purpose of the present study was to assess $\mathrm{GH}$ response to apomorphine in major depressed in-patients with a history of highly lethal suicide attempt compared to depressed patients with a low lethal lifetime suicide attempt history and nonattempters. We also controlled some confounding factors such as gender, age, severity of depression, and level of psychomotor retardation.

\section{Methods}

\subsection{Subjects}

The study was performed in a sample of 26 male in-patients fulfilling DSM-IV (APA, 1994) criteria for major depressive disorder. Patients had a mean age \pm SD of 41.6 \pm 13.2 years. Diagnostic assessments were performed by two clinical and research psychiatrists (WP and AGM). Patients were individually matched for age (within three years) with 26 major depressed male in-patients with no history of suicidal behavior. Due to the influence of estrogens on hormonal responses, women were excluded from the study. We also excluded patients with psychotic symptoms or a diagnosis of schizotypic personality disorder. Both groups included one bipolar patient. Diagnosis of melancholia was present in seven patients in the suicide attempters group and in nine subjects in the control goup. Overweight $35 \%$ above the ideal body weight) patients were excluded from the study. Moreover, there was no significant difference in mean weight between both groups. All patients had a score of at least 15 on the 21-item Hamilton depression scale (Hamilton, 1960) at the end of a drug-free period of at least two weeks (five weeks in case of fluoxetine prescription) during which patients were only allowed occasional low doses of benzodiazepines if necessary.

Past history of suicide attempt was based on interviews of the patient and their family. The lethality of the attempt was assessed using the SADS lethality scale (Spitzer and Endicott, 1977) refering to the most lethal lifetime suicide attempt. Suicide attempters were divided into high-lethality (score $\geq 4$, mean $\pm S D=5.3 \pm 0.7$, 1.6 attempts) and low-lethality (score $<4$, mean $\pm \mathrm{SD}=2.6 \pm 0.5,1.2$ attempts) suicide. The time interval between the most lethal suicide attempt and the neuroendocrine test ranged from two to 150 weeks (mean $\pm \mathrm{SD}=27.9 \pm 46.9$ weeks).

All patients were free of medical illness as evidenced by history, medical examination, electrocardiogram, chest X-ray, electroencephalogram, and routine laboratory 
tests. Patients with a basal systolic blood pressure less than $100 \mathrm{~mm} \mathrm{Hg}$ were excluded from the study. Moreover, in order to be included, patients had to present a basal ( $t 0) \mathrm{GH}$ level less than $5 \mathrm{ng} / \mathrm{ml}$ before the pharmacological challenge. The exclusion of subjects with basal GH values $>5 \mathrm{ng} / \mathrm{ml}$ is recommended because "prestimulator" healthy volunteers tend to respond significantly less to a noradrenergic challenge than healthy volunteers with low basal values (Laakmann, 1990). Finally, patients gave informed consent for their participation in neuroendocrine studies at the University Hospital of Liège, Belgium.

\subsection{Neuroendocrine test procedure}

The apomorphine test was performed at bedrest after an overnight fast. At 0700 $\mathrm{h}$, an indwelling catheter was inserted in a forearm vein. Blood samples of $10 \mathrm{ml}$ were collected at $-20,0,+20,40,60$ and $120 \mathrm{~min}$ after injection at $0800 \mathrm{~h}$ of apomorphine $(0.5 \mathrm{mg}$ diluted in saline to obtain $0.5 \mathrm{ml})$ subcutaneously.

GH was measured with a double antibody radioimmunoassay (Franchimont, 1968), with intra-assay and inter-assay coefficients of variation of, respectively, $13.3 \pm 4.7 \%$ and $14.8 \pm 9.6 \%$ and a detection limit of $0.2 \mathrm{ng} / \mathrm{ml}$.

The cut-off GH peak following apomorphine was defined as $5 \mathrm{ng} / \mathrm{ml}$ (Ansseau et al., 1984). In a previous study, all seven controls (100\%) tested with apomorphine $(0.5 \mathrm{mg})$ presented $\mathrm{GH}$ responses higher than $5 \mathrm{ng} / \mathrm{ml}$ (Rotrosen et al., 1976). More recently, in a sample of 12 normal volunteers, we observed $\mathrm{GH}$ responses above 5 $\mathrm{ng} / \mathrm{ml}$ in 11 of $12(92 \%)$ subjects. Moreover, individual peaks following apomorphine $(0.75 \mathrm{mg})$ were higher than $5 \mathrm{ng} / \mathrm{ml}$ in 114 of $121(94 \%)$ normal subjects (reviewed by Ansseau et al., 1982).

\subsection{Data analysis}

GH responses to apomorphine were measured by GH peak values following injection. Analyses were performed using absolute $\mathrm{GH}$ values as well as differences related to basal ( $t 0)$ levels (relative values). Since the correlation between absolute and relative values were very high $(r>0.98)$, only absolute values are reported here. Moreover, since peak and area under the curve values are generaly highly correlated $(r>0.97)$, we decided to choose GH peak values as the measure of maximal hormonal response to apomorphine. Comparisons between groups used analysis of variance (ANOVA) or covariance when necessary. We also used Pearson's correlation coefficient and chi-square procedure.

\section{Results}

We did not observe any statistically significant difference between groups for HAMD scores $(26.2 \pm 7.2$ in suicide attempters vs $23.5 \pm 5.1$ in non-attempters, $F=2.5$, $\mathrm{df}=1,50, P=0.12)$. $\mathrm{GH}$ was not correlated with age $(r=-0.18, P=0.21)$ or psychomotor retardation sub-scale scores of the HAMD $(r=-0.11, P=0.43)$. Mean GH peak 
responses to apomorphine differed significantly between suicide attempters and nonattempters (mean $\pm \mathrm{SD}$ ): for $\mathrm{GH}$ peak, $6.3 \pm 5.1 \mathrm{ng} / \mathrm{ml}$ vs $15.8 \pm 14.2 \mathrm{ng} / \mathrm{ml}, F=10.3$, $\mathrm{df}=1,50, P=0.002$ (Fig. 1). Adding age, HAMD and psychomotor retardation subscale scores in an ANCOVA set-up only decreased the $F$-value from 10.3 to 9.8 $(P=0.003)$. Thirteen of the $26(50 \%)$ patients with a history of suicide attempts exhibited a blunted $\mathrm{GH}$ response to apomorphine compared to 6 of 26 (23\%) nonattempters (chi square $=4.06, \mathrm{df}=1, P=0.04$ ). Moreover, time interval between the most lethal suicide attempt and the neuroendocrine test was not correlated with $\mathrm{GH}$ responses $(r=-0.36, P=0.15)$.

We did not observe any statistically significant differences between high lethality $(n=14)$ and low lethality $(n=12)$ suicide attempters for age $(F=3.61, P=0.07)$, HAMD scores $(F=0.43, P=0.51)$, psychomotor retardation subscale scores of HAMD $(F=3.11, P=0.09)$ and diagnosis of melancholia $(F=1.15, P=0.29)$. Mean GH peak responses to apomorphine did not differ between depressed patients with a high lethal lifetime suicide attempt history and patients who made low lethal lifetime suicide attempt: for $\mathrm{GH}$ peak, $5.6 \pm 3.1 \mathrm{ng} / \mathrm{ml}$ vs $7.0 \pm 6.8 \mathrm{ng} / \mathrm{ml}, F=0.43, \mathrm{df}=1,24, P=0.51$. An ANCOVA analysis with age, melancholia, HAMD and HAMD psychomotor retardation subscales scores as covariates decreased the $F$-value from 0.43 to 0.13 $(P=0.72)$. Moreover, we did not observe any significant correlation between $\mathrm{GH}$ responses to apomorphine and SADS lethality scores $(r=-0.08, P=0.71)$.

\section{Discussion}

Our results are consistent with the role of the dopaminergic system, and in particular of D2-receptors, in the biology of suicidal behavior. Indeed, male depressed

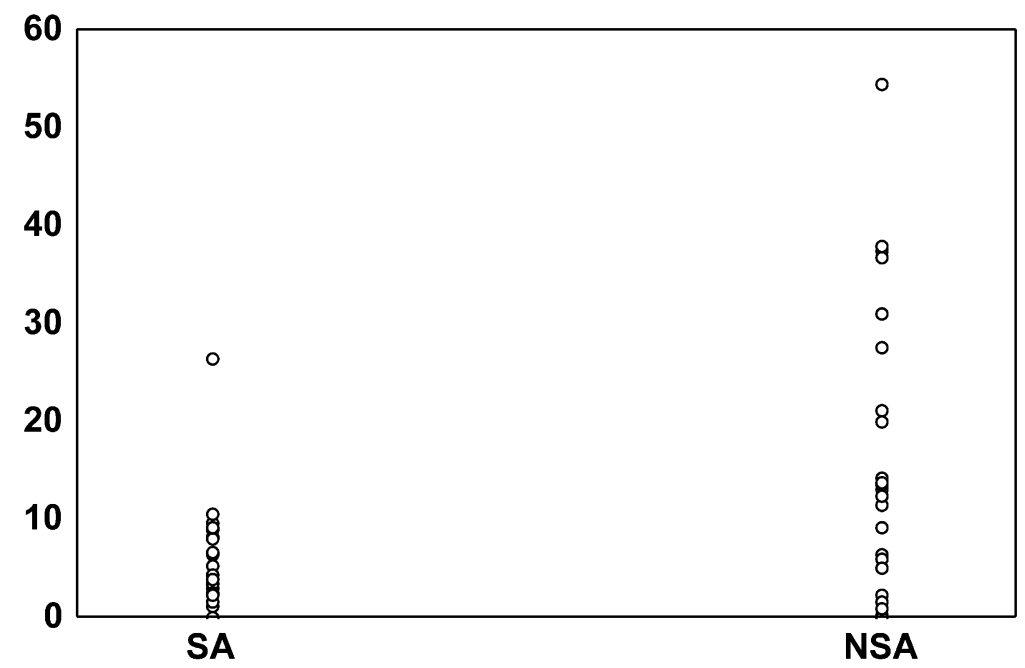

Fig. 1. GH responses to apomorphine in suicide attempters (SA) compared to nonattempters (NSA) $(F=10.3, \mathrm{df}=1,50, P=0.002)$. 
suicide attempters exhibited a blunted GH response to apomorphine compared to depressed controls who never attempted suicide. Moreover, we did not observe any significant difference between high and low lethality suicide attempters suggesting that both groups could share some biological disturbances, and in particular at the level of the dopaminergic system.

The results of the present study are in agreement with our previous studies in which we demonstrated an impaired GH response to apomorphine in depressed and non-depressed suicide attempters compared to non-attempters (Pitchot et al., 1992). Several studies assessing CSF HVA levels in suicide attempters have also suggested a relationship between suicidality and dopaminergic function (Engström et al., 1999). However, these indirect measures of dopamine activity could be much more in relationship with the depressive spectrum rather than with the suicidal dimension. Indeed, decrease in CSF HVA levels is frequently observed in CSF studies (Goodwin and Jamison, 1990). In 1981, Träskman-Bendz et al. observed low CSF HVA concentrations in depressed suicide attempters, but not in attempters with other psychiatric diagnosis compared to controls. In fact, most studies reporting an association between measures of dopamine function and suicidal dimension are performed in depressed patients or in heterogenous samples of psychiatric patients. In fact, dopaminergic hypoactivity in suicide attempters could be in relationship with some psychosocial risk factors related to suicidal behavior rather than with diagnosis as such.

Our results have to be taken with caution due to the small sample size and to the lack of specific assessment of impulsivity, impulsive aggression and Cluster B Personality Disorder co-morbidity. Moreover, a confounding factor is the possible influence of antidepressant treatment on GH response to apomorphine. Indeed, several reports have suggested that tricyclics may impair the $\mathrm{GH}$ response to clonidine for periods longer than three weeks following discontinuation (Schittecatte et al., 1989). However, previously, we assessed the GH response to apomorphine in 11 male DSM-III-R major depressive inpatients who had never received antidepressant therapy compared with 11 normal controls and 11 major depressive in-patients drugfree for at least two weeks, and demonstrated that a wash-out period of two weeks was sufficient to assess GH response to apomorphine (Pitchot et al., 1995). Another problem is that the $\mathrm{GH}$ response to apomorphine provides information about the sensitivity of D2 receptors at the hypothalamic level and we do not know to what extent a hypothalamically mediated endocrine response is informative about the dopaminergic function in mesocortical and mesolimbic systems. Despite these limitations, the apomorphine test remains a very interesting technique for investigating dopaminergic system providing an indirect approach of the functional state of the dopaminergic system in vivo. In comparison, CSF concentration of HVA is a weak indicator of central dopaminergic function providing information on presynaptic but not postsynaptic activity. CSF studies are unable to state if the decreased in DA turnover is a consequence of dopaminergic cell loss, a diminished availability of tyrosine in the cell, presynaptic or postsynaptic receptors dysfunction, and therefore to determine which type of receptor is involved in suicidal behaviour. Moreover, lumbar puncture necessary for CSF analysis is a very invasive technique, not so easy to use in clinical practice. Therefore, taking account of some limitations, the 
apomorphine test could be considered as a possible biological marker of suicidal behaviour in affective disorders and help the clinician in the assessement of suicide risk.

In conclusion, the results of the present study support a role for dopamine in the biology of suicidal behavior. More specifically, an impaired GH response to apomorphine could be a marker of suicide risk. However, several methodological problems should be studied to improve the real utility of the apomorphine test in clinical practice.

\section{References}

American Psychiatric Association, 1994. Diagnostic and Statistical Manual of Mental Disorders, 4th ed. APA, Washington, DC.

Ansseau, M., Doumont, A., Legros, J.J., 1982. Evidence for a catecholaminergic deficiency in primary depression by means of specific neuroendocrine tests. Presented at the joint meeting of the Association Française de Psychiatrie Biologique and of the British Association for Psychopharmacology, Paris.

Ansseau, M., Scheyvaerts, M., Doumont, A., Poirrier, R., Legros, J.J., Franck, G., 1984. Concurrent use of REM latency, dexamethasone suppression, clonidine, and apomorphine tests as biological markers of endogenous depression: a pilot study. Psychiat Res. 12, 261-272.

Arranz, B., Blennow, K., Eriksson, A., Mansson, J.E., Marcusson, J., 1997. Serotonergic, noradrenergic, and dopaminergic measures in suicide brains. Biol. Psychiatry 41, 1000-1009.

Asberg, M., 1997. Neurotransmitters and suicidal behavior: the evidence from cerebrospinal fluid studies. Ann. N.Y. Acad. Sci. 836, 158-181.

Bowden, C., Cheetham, S.C., Lowther, S., Katona, C.L.E., Crompton, M.R., Horton, R.W., 1997. Reduced dopamine turnover in the basal ganglia of depressed suicides. Brain Res. 769, 135-140.

Crow, T.J., Cross, A.J., Cooper, S.J., Deakin, J.F., Ferrier, I.N., Johnson, J.A., Joseph, M.H., Owe, F., Poulter, M., Lofthouse, R., 1984. Neurotransmitter receptors and monoamine metabolites in the brains of patients with Alzheimer-type dementia and depression and suicides. Neuropsychopharmacology 23, $1561-1569$.

Engström, G., Alling, C., Blennow, K., Regnéll, G., Träskman-Bendz, L., 1999. Reduced cerebrospinal HVA concentrations and HVA/5-HIAA ratios in suicide attempters. Monoamine metabolites in 120 suicide attempters and 47 controls. Eur. Neuropsychopharmacol. 9, 399-405.

Franchimont, P., 1968. Le dosage radioimmunologique de l'hormone de croissance humaine. Cah. Med. Lyonnais 44, 887-898.

Goodwin, F.K., Jamison, K.R., 1990. In: Manic-Depressive Illness. Oxford University Press, New York and Oxford, pp. 416-502.

Hamilton, M., 1960. A rating scale for depression. J. Neurol. Neurosurg. Psychiat. 23, 56-62.

Laakmann, G., 1990. Psychopharmacoendocrinology and Depression Research. Springer-Verlag, Berlin.

Mann, J.J., Malone, K.M., 1997. Cerebrospinal fluid amines and higher-lethality suicide attempts in depressed inpatients. Biol. Psychiatry 41, 162-171.

Mann, J.J., Stoff, D.M., 1997. A synthesis of curent findings regarding neurobiological correlates and treatment of suicidal behavior. Ann. N.Y. Acad. Sci. 836, 352-363.

Ohmori, T., Arora, R.C., Meltzer, H.Y., 1992. Serotonergic measures in suicide brain: the concentration of 5-HIAA, HVA, and tryptophan in frontal cortex of suicide victims. Biol. Psychiatry 32, 57-71.

Pandey, G.N., 1997. Altered serotonin function in suicide: evidence from platelet and neuroendocrine studies. Ann. N.Y. Acad. Sci. 836, 182-200.

Pitchot, W., Hansenne, M., Gonzalez Moreno, A., Ansseau, M., 1992. Suicidal behavior and growth hormone response to apomorphine test. Biol. Psychiatry 31, 1213-1219.

Pitchot, W., Hansenne, M., Gonzalez Moreno, A., Ansseau, M., 1995. Effect of previous antidepressant therapy on the growth hormone response to apomorphine. Neuropsychobiology 32, 19-22. 
Pitchot, W., Reggers, J., Pinto, E., Hansenne, M., Fuchs, S., Pirard, S., Ansseau, M., 2001. Reduced dopaminergic activity in depressed suicides. Psychoneuroendocrinology 26, 331-335.

Rotrosen, J., Angrist, B.M., Gershon, S., Sachar, E.J., Halpern, F.S., 1976. Dopamine alteration in schizophrenia: neuroendocrine evidence. Psychopharmacology 51, 1-7.

Roy, A., Agren, H., Pickar, D., Linnoila, M., Doran, A.R., Cutler, N.R., Paul, S.M., 1986. Reduced CSF concentrations of homovanillic acid and homovanillic acid to 5-hydroxyindolacetic acid ratios in depressed patients: relationship to suicidal behavior and dexamethasone nonsuppression. Am. J. Psychiatry 143, 1539-1545.

Roy, A., De Jong, J., Linnoila, M., 1989. Cerebrospinal fluid monoamine metabolites and suicidal behavior in depressed patients: a 5-years follow-up study. Arch. Gen. Psychiatry 46, 609-612.

Schittecatte, M., Charles, G., Machowski, R., Wilmotte, 1989. Tricyclic wash-out and growth hormone response to clonidine. Br. J. Psychiatry 154, 858-863.

Spitzer, R.L., Endicott, J., 1977. Schedule for Affective Disorders and Schizophrenia (SADS), 3rd ed. New York State Psychiatric Institute, Biometrics Research, New York.

Träskman-Bendz, L., Asberg, M., Bertilsson, L., Sjöstrand, L., 1981. Monoamine metabolites in CSF and suicidal behavior. Arch. Gen. Psychiatry 38, 631-636.

Träskman-Bendz, L., Alling, C., Alsén, M., Regnéll, G., Simonsson, P., Öhman, R., 1993. The role of monoamines in suicidal behavior. Acta Psychiatr. Scand. 371 (Suppl.), 45-47. 